\title{
Idea Generation on Social Media Based Brainstorming Session
}

\author{
Atikah Mauluddiyah, Diina Itsna Annisa, Dila Fipta W Sari \\ Pendidikan Kejuruan, Universitas Negeri Malang, Malang, Indonesia \\ Neini Ratmaningsih \\ ${ }^{2}$ Program Studi Pendidikan Ilmu Pengetahuan Sosial, Universitas Pendidikan Indonesia, Bandung, Indonesia \\ E Nugraha \\ Ilmu Komputer, Universitas Pendidikan Indonesia, Bandung, Indonesia
}

\begin{abstract}
The rise of forums that utilize communication technology today is one of them using a brainstorming method to facilitate discussion. Brainstorming is a method to explore the ideas of all participants in a forum. The purpose of this research is to understand the effectiveness and result of applying brainstorming method between direct discussion and by using online method (group WhatsApp). The advantages of the brainstorming method are the pattern that allows each member of the discussion to express their opinions without fear or doubt. Brainstorming is applied to direct and online discussions (using WhatsApp group) on Graduate students of Universitas Negeri Malang. The result shows that the brainstorming model is more applicable and effective for online discussion compared to direct discussion. In terms of language and psychology, we found flexibility and ease when using online discussions. It can be said that the use of Brainstorming methods is more effective and successful in online discussions.
\end{abstract} Media.

Keywords- Brainstorming Session; Direct Meeting; Social

\section{INTRODUCTION}

In the past, people popularly did a discussion by face to face in a room or outdoors. The discussion would only be started if all of the participants were present in the forum. It could not run well if some of the participants were absent. Consequently, if you were a participant and absent, you would miss the information in the discussion. Today, there are many methods of discussion. The development of technology and communication adds the variety of the methods. Nowadays, a discussion is not merely face to face. A discussion can be made even though the participants are in the different places. We have what we call "internet" to facilitate this kind of discussion. Popularly, we call this discussion as a brainstorming.

Brainstorming, defined as generating, sharing, and combining ideas about a problem or task by more than one individual[1] [2]. Brainstorming is one of the problem solving and creative village provocation strategies [3] [4]. The
Brainstorming process is more biased toward the quantitative of the opinions conveyed [5] [6]. The process of discussion, assessment, evaluation, and possibility applied will be done in the next period.

Brainstorming sessions have been widely investigated in terms of both psychological and practical perspectives making it possible to improve interpersonal relationships. Design Thinking Observatories carefully monitor the behavior of team members, registering their actions and events to analyze, whether the discussion is heading in the right direction[7]. Brainstorming activity is an activity that accommodates idea or idea from the member of the group, in this research will found which media is most effective used in discussion activity. The data should be legible to create a shared understanding among all team members because people might have diverse individual perspectives that guide their interpretations [7]. This article aims to examine how important the role of brainstorming is and through what media discussion members play an active role in discussion activities

Using brainstorming with online media that has benefits that are different from anonymous and non-existent statuses [8]. The disadvantages of the Brainstorming method are: (1) requiring much time estimation; (2) productivity depends on the ability and quality of member orientation; (3) the discussion process is conducted outside the brainstorming forum; (4) the truth and error of opinion cannot be immediately known, and (5) the topic of discussion is potentially widespread.

\section{METHOD}

In this study, participants will be given a problem, in this case, discussing how to get assistance in journal publishing. Discussion activities will take place are 1 st to 5 th weeks, during which time the discussion members are expected to be able to 
provide brilliant ideas about the problems that already exist. Discussion activities will take place in 2 forums, the first direct discussion forums and discussions through online media (WhatsApp). The population of this study is all postgraduate students of Universitas Negeri Malang, with random samples of students who are interested in discussing this issue.

Respondents in this study are post-graduate students. Respondents focus on 1 class which will be examined from the direct discussion and social media utilization in the form of WhatsApp for brainstorming. The respondent is Pendidikan Kejuruan of 2017 offering B and C. Data obtained from observations made by researchers to the respondents either the discussion directly or through WhatsApp. The study was conducted by observation in the class and WhatsApp group. Observation of direct brainstorming discussions conducted in post-graduate vocational education Universitas Negeri Malang. Researchers observe 18 respondents in brainstorming from both direct discussion and WhatsApp groups.

Social Media Brainstorming is done during college hours while group WhatsApp by starting the topic. A Social Media Brainstorming (SMB) is done during course hours whereas the WhatsApp discussion is done anytime as long as there is a topic to e discussed. A Social Media Brainstorming (SMB), is started by throwing an idea to be discussed in the group. Such as by giving a topic about how to upload an international journal. The researcher will see and observe the response of the group corresponds to the given topic.

The technique used is Brain-Netting (Brainstorming Online) by throwing an idea into or question about something to an existing group. Then the other members of the group put forward their opinions one by one according to the understanding of each member. The process of giving opinion continue until the last opinion, then draw conclusions and discuss it on another occasion.

While direct brainstorming techniques use Round Robin Brainstorming techniques. This technique is done by giving an opportunity for each member to participate. So, when one group of participants convey his idea then the other participant are silent and listen. When an opinion has been submitted, it is a turn of the other member to convey and others who are not in the turn must be silent and listen too. This method continues until all the participants' opinions are gathered. Finally, a conclusion is drawn or a new session of discussion will be held at another time.

\section{RESULTS AND DISCUSSION}

The study was conducted for 5 weeks. The research was done by observing brainstorming in class and social media through WhatsApp application. Researchers observed the class activities and discussion process conducted in the forums in WhatsApp. The researchers recorded and observed brainstorming activities. The researchers did a good documentation of Direct Meeting Brainstorming (DMB) and
Social Media Brainstorming (SMB). The results of the observations made in both DMB and SMB activities are illustrated in the documentation of DMB and SMB objections, which conclusions from the research activities are presented in tabular form.

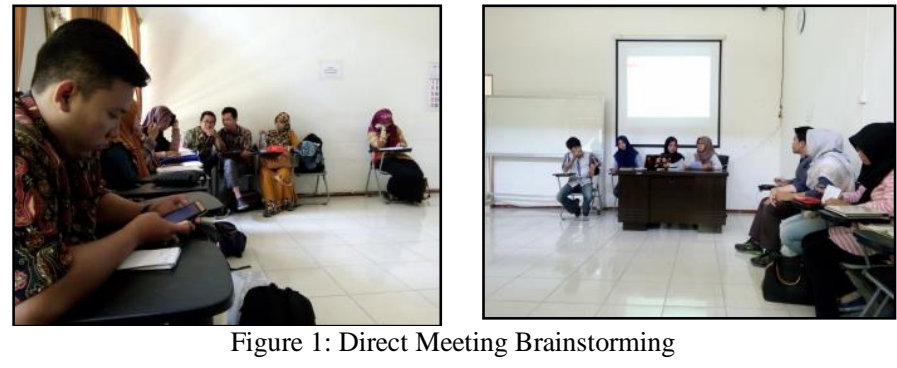

Figure 1 shows that some participants did not focus on a Direct Meeting Brainstorming (DMB). The Direct Meeting Brainstorming (DMB) activities could not run well due to some participants couldn't focus on the activities. We can see some of the participants will enjoy playing their mobile phone during the discussion. It happened due to a lack of focus or the uninteresting topic so that participants could not get into the discussion.

Direct discussion activities in the implementation using the formal language and psychologically the participants of the discussion were required to ask to live in the atmosphere of the discussion directly. Discussions conducted directly in accompanied by a lecturer. From several discussion, it can be seen that the lecturer tent to perform an active role in the discussion, not the participants.

While in the online discussion activities, in the execution of discussion or convey the opinion, the participants of the discussion used often a non-formal language. Discussion activities also run in a relaxing manner so that each participant can express his/her opinion treaty. This online discussion activity has no lecturers, so the participants can be more relaxed and use non-formal language. But in the Social Media Brainstorming (SMB), there are also some discussions followed by lecturers.

Social media can be defined as a form of communication through which users interact among people in which they create, freely share, exchange and discuss information, ideas, personal messages, and other content about each other and their lives using a multimedia mix of personal words, pictures, videos, and audio, utilizing online platforms while they are connected to the Internet [9]. In a study conducted by Johnson Yeboah and George Dominic Ewur in the title The Impact of Whatsapp Messenger Usage on Students Performance in Tertiary Institutions in Ghana. mentioned that the use of WhatsApp can improve the performance of tertiary students if used positively. However, if used in excess will have a negative impact on its users [10]. 


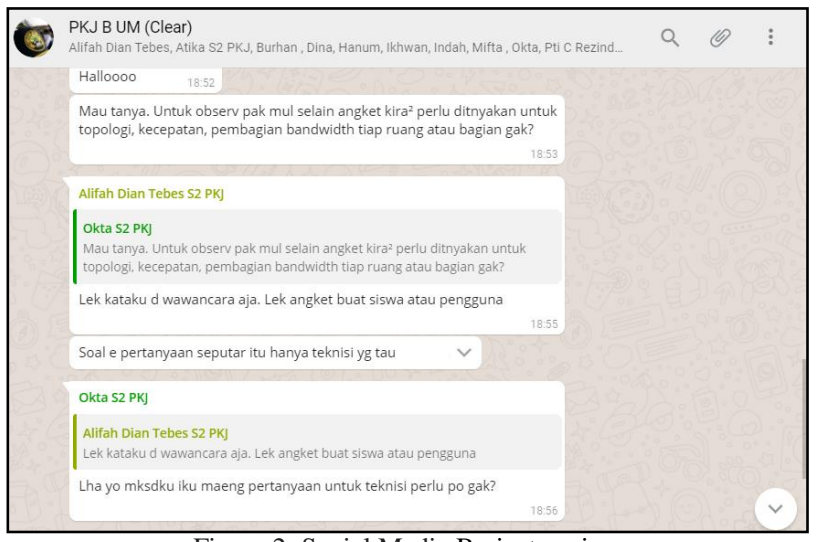

Figure 2: Social Media Brainstorming

In Figure 2, an example of Social Media Brainstorming (SMB) using WhatsApp group is illustrated. The figure briefly discusses the questionnaire to be used in KDJK courses. The glimpse of the conversation such as "Want to ask, for KDJK observations in addition to questionnaire approximately need to be asked for topology, speed, bandwidth division per space or part?" Then responded by other participants who essentially like this "if I say in the interview only .. if the questionnaire for students or users, because the question about it only technicians know about that". In the conversation, participants used the non-formal language they use every day. Other than that the topic discussed was the discussion of the subject task at the next meeting. this makes students responded quickly and participate actively in the group WhatsApp. This was because that, the forum was only followed by post graduated only, no lecturers, so they used non-formal language. Therefore, Social Media Brainstorming could run in a relaxed and participant can express opinions casually.

This research, both Direct Meeting Brainstorming (DMB) and Social Media Brainstorming (SMB), were done in 5 weeks only due to a reason that the DMB could not be done longer since there where a mid-term test and many holidays. The researcher decided to end the discussion because he/she was quite sure that the result would be the same if the discussion is made longer.

TABLE I. RESULTS OF BRAINSTORMING ACTIVITIES OF DIRECT AND ONLINE DISCUSSIONS

\begin{tabular}{|c|c|c|c|c|c|c|}
\hline \multirow{2}{*}{ Week } & \multicolumn{3}{|c|}{ DMB } & \multicolumn{3}{c|}{ SMB } \\
\cline { 2 - 7 } & $\sum$ discussion & $\begin{array}{c}\bar{X} \text { time } \\
(\text { secon }\end{array}$ & & $\begin{array}{l}\sum_{\text {topic }} \\
\text { ion }\end{array}$ & $\begin{array}{l}\bar{X} \text { time } \\
\text { (secon }\end{array}$ & \begin{tabular}{l}
$\sum_{\text {topic }}$ \\
\hline $\mathbf{1}$
\end{tabular} \\
\hline $\mathbf{2}$ & 4 & 5850 & 4 & 6 & 13980 & 4 \\
\hline $\mathbf{3}$ & 3 & 5700 & 2 & 5 & 28320 & 5 \\
\hline $\mathbf{4}$ & 1 & 5800 & 3 & 7 & 36900 & 7 \\
\hline $\mathbf{5}$ & 6 & 5300 & 1 & 8 & 23940 & 7 \\
\hline $\begin{array}{c}\text { amou } \\
\text { nt }\end{array}$ & 16 & 26250 & 16 & 40 & 135840 & 34 \\
\hline
\end{tabular}

Table 1 shows the result of research on DMB and SMB. This study was conducted for 5 weeks with a topic on each discussion. In the first week, there was a DMB discussion activity with 4 times discussion and SMB with 6 discussion activities. But in terms of time, SMB is superior to DMB. Topics covered in SMB from KDJK questionnaires, KDJK interviews, add the list of KDJK questionnaires, and table of contents to SPK books. Meanwhile, the DMB topics in the discussion activities tailored to the courses that are taking place in the week.

The second week of SMB is superior to DMB where there are 2 discussions and 5 DMB discussed thesis proposal, UTS material for the statistics course, SI consultation and SPK Discussion, excel data from post UM registration and Trello.

In the third week, there was a significant increase in the number of live discussion discussions in SMB where the SMB had 7 DMB while DMB consists of 3 discussion activities. The topic of online discussion on the direction discussed had been taught at SMKN 8 Malang, Task Questionnaire KDJK, an announcement of AI journal revision, material management industry for a midterm exam, midterm exam of the Landasan Pembelajaran course, college statistics change and lecture on Wednesday.

The fourth week could be seen from Table 1 that SMB has 7 topics of discussion on data and analysis of KDJK questionnaires, material management industry for midterm exam, materials for the semester exam of the Landasan Pembelajaran course, materials for the semester exam of the Management Industry course, Seminar Proposal lecture announcement, college statistics, and SI \& SPK confirmation. While DMB, there was only one discussion activity. it was because that in that week many lecturing activities were empty so that there was only happened once discussion activity in that week.

The fifth week of DMB activity increased from the previous weeks. Each discussion activity both SMB and DMB there were 6 discussion activities. Online discussions were about the confirmation of classes for KDJK, lecture, lecture, statistics course, AI journal, SI questionnaire, class jacket.

At the 5th week, as can be seen in the table, there was a very significant increase in the activities. This increasing activity occurred because the topics that need to be discussed had developments and follow-up especially in the course of statistics where the course was done 2 times a week and requires further discussion about replacement lectures, materials and class determination (direct discussion). In addition to the fact that in the 4th week there was no lecture, the discussion should be done in the previous week, conducted at week 5 . This conversation was done through WhatsApp and could be found that this social media. Moreover, this could equip and facilitate graduate students in establishing communication, knowledge and social

Internal factors derived from within the students is a factor associated with learning psychology. In this internal factors, there are four factors that need to be considered and overcome, 
namely physiological factors, psychological factors, fatigue factors and factors of forgetting. Psychological factors include; intelligence, attention, interest, talent, and motivation. First; Intelligence. Intelligence is a skill that consists of three types, namely; (1). The ability to confront and adapt to new situations appropriately and effectively, (2). Knowing or using abstract concepts effectively and (3). Know the relation and learn it quickly. Attention is an activated soul, the soul is just fixed on an object. To obtain good learning outcomes, students give full attention to the material they learn, because if the lesson material is not a concern for the students will cause boredom so that students do not like to learn again. So, the psychological condition of a person can affect the learning activities, as well as in the discussion activities both conducted directly or online. Indirect discussion activity, psychological discussion participants are burdened with the lecturers but in the discussion, online discussion participants can be more relaxed and calm in participating and participating in online discussion activities [11].

Brainstorming is used to build ideas by each member of the discussion group to convey their ideas effectively and equitably. The elements of effective communication is a messenger conveys clearly, chooses the right media, and asks for a response. As for the receiver of the message, it will receive the message with full concentration and provide feedback [12]. In the Brain-Netting (Brainstorming Online) model, it can be seen that effective communication can be created, both in terms of conveying the idea clearly, appropriate media through online, and requesting response from other members. On the other hand, the recipient of the message or listening idea with the concentration is seen from the chat replies that match the topic of discussion or the issue under discussion. In Round Robin Brainstorming, effective communication can also be created, just not as big as when using online media. This can be seen in terms of the number of members who convey their ideas during discussions in progress. Known from the observation, that the number of brainstorming ideas on Brain-Netting (Brainstorming Online) more than Round-Robin Brainstorming.

Based on observations made on both DMB and SMB as presented in the table, it can be noted that there is a significant difference between DMB and SMB discussions. In DMB, the number of discussions is proportional or almost equal to the number of topics available. While in the discussion conducted by using SMB, in the discussion conducted can be a discussion activity by continuing the same topic in previous discussion activities. As well as the time spent in the two discussions, direct discussion conducted in the classroom only has time during the course, while the discussion using WhatsApp media, because it is not bound by the time of discussion activities lasted longer. Because the discussion using WhatsApp media is done casually and informal languages are spoken except in group MK SI and SPK 2017 so it runs longer than direct discussion done in class.
In the study found that online Brainstorming is able to generate more ideas than directly. The weight of the ideas conveyed is also quite good or in the sense of not giving the origin of the idea. If indirect discussion gives each member an average idea, on the SMD model obtained more than two times the member gives his idea. from here it can be said that the effectiveness of Brainstorming is more felt using online discussion than direct discussion.

In terms of language, it can be seen that the language used in Brain-Netting (Brainstorming Online) is more flexible than Round-Robin Brainstorming. As the results of the study [13] state that $80 \%$ feel more comfortable discussing in social media (WhatsApp messenger) with lecturers in it. Still, in the same research results, it is known that the participants of the discussion agreed $100 \%$ maintain formality if in the discussion group there are lecturers, and $90 \%$ stated need to keep the suit if there is no lecturer in the group. As shown in this study, it can be seen that the Brain-Netting (Brainstorming Online) process also runs more flexible in terms of language than Round-Robin Brainstorming.

\section{CONCLUSION}

It can be concluded that Social Media Brainstorming (SMB) is better than Direct Meeting Brainstorming (DMB). It is better in terms of the bigger amount of ideas that appear (since the participants do not have to use formal language, they are free to express their ideas) and psychological effect (in Special Media Brainstorming (SMB), participants fell relax, more comfortable and unstress while in DMB, the atmosphere is more tense and formal so that participants cannot enjoy the discussion). In summary, this research related to a specific reason why someone is more comfortable in using Social Media Brainstorming (SMB).

\section{REFERENCES}

[1] E. Javadi, J. Gebauer, and J. Mahoney, "The Impact of User Interface Design on Idea Integration in Electronic Brainstorming: An AttentionBased View The Impact of User Interface Design on Idea Integration in Electronic Brainstorming: An Attention-Based View," J. Assoc. Inf. Syst., vol. 14, no. 1, pp. 1-21, 2013.

[2] C. Bezzi, “Evaluational Brainstorming," Sociol. Mind, vol. 01, no. 04, pp. 151-155, 2011.

[3] A. N. M. AlMutairi, "The Effect of Using Brainstorming Strategy in Developing Creative Problem Solving Skills among Male Students in Kuwait: A Field Study on Saud Al-Kharji School in Kuwait City,” J. Educ. Pract., vol. 6, no. 3, pp. 136-145, 2015.

[4] Sabarun, "Using Brainstorming Technique in Writing Time- Order Paragraph At the Second Semester English Department ... Writing Paragraph Across the Different Level of," Proc. 1st Natl. Conf. English Lang. Teach., vol. ISSN: 2502, no. October 2014, pp. 66-85, 2015.

[5] C. E. Rizi, M. Najafipour, F. haghani, and S. Dehghan, "The Effect of the Using the Brainstorming Method on the Academic Achievement of Students in Grade Five in Tehran Elementary Schools," Procedia - Soc. Behav. Sci., vol. 83, no. April, pp. 230-233, 2013.

[6] C. Boddy, "The Nominal Group Technique: an aid to Brainstorming ideas in research," Qual. Mark. Res. An Int. J., vol. 15, no. 1, pp. 6-18, 2012.

[7] L. B. Jerzy and Z. Wilimowska, "Leszek Borzemski Jerzy Świątek Zofia Wilimowska," in Information Systems Architecture And Technology: 
Proceedings of 38th International Conference on Information Systems Architecture And Technology - ISAT 2017 - Part II, 2017, pp. 128-137.

[8] P. B. Paulus, N. W. Kohn, L. E. Arditti, and R. M. Korde, "Understanding the Group Size Effect in Electronic Brainstorming," Small Gr. Res., vol. 44, no. 3, pp. 332-352, 2013.

[9] E. Alwagait, B. Shahzad, and S. Alim, "Impact of social media usage on students academic performance in Saudi Arabia," Comput. Human Behav., vol. 51, no. October 2017, pp. 1092-1097, 2015.
[10] J. Yeboah and G. D. Ewur, "The impact of Whatsapp messenger usage on students performance in tertiary institutions in Ghana," J. Educ. Pract., vol. 5, no. 6, pp. 157-164, 2014.

[11] Nidawati, "Belajar Dalam Perspektif Psikologi Dan Agama," Pionir, vol. 1 , no. 1, pp. 13-28, 2013.

[12] N. H. Salisah, Psikologi komunikasi. Surabya, 2007.

[13] M. D. A. N. Adab, "Whatsapp messenger dalam tinjauan manfaat dan adab," Wahana Akad., vol. 3, no. 1, pp. 51-66, 2016. 